Document downloaded from:

http://hdl.handle.net/10251/139768

This paper must be cited as:

Grande, E.; Fagone, M.; Rotunno, T.; Bertolesi, E.; Milani, G. (15-0). Coupled interfacebased modelling approach for the numerical analysis of curved masonry specimens strengthened by CFRP. Composite Structures. 200:498-506.

https://doi.org/10.1016/j.compstruct.2018.05.118

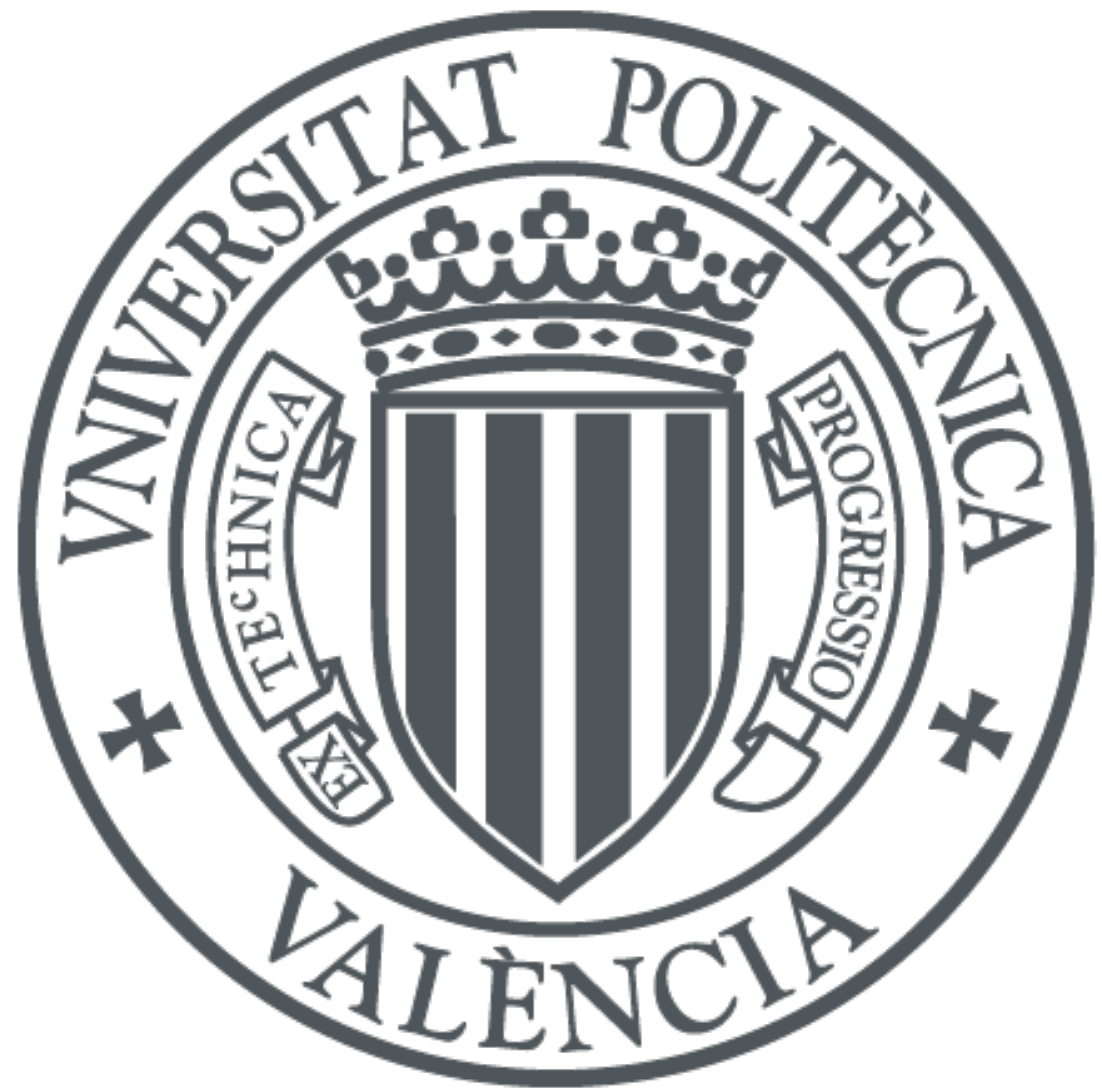

The final publication is available at

https://doi.org/10.1016/j.compstruct.2018.05.118

Copyright Elsevier

Additional Information 


\title{
Coupled interface-based modelling approach for the numerical analysis of curved masonry specimens strengthened by CFRP
}

\author{
Ernesto GRANDE ${ }^{(1)}$, Mario FAGONE ${ }^{(2)}$, Tommaso ROTUNNO ${ }^{(3)}$, Elisa BERTOLESI ${ }^{(4)}$, Gabriele \\ MILANI $^{*(5)}$ \\ (1) Department of Sustainability Engineering, University Guglielmo Marconi, Via Plinio 44, 00193 Rome (Italy) \\ (2) Dipartimento di Ingegneria Civile e Ambientale (DICA), Università degli Studi di Firenze, Piazza Brunelleschi \\ 6, 50121 Florence (Italy)
}

(3) Dipartimento di Architettura (DiDA), Università degli Studi di Firenze, Piazza Brunelleschi 6, 50121 Florence (Italy)

(4) ICITECH, Universitat Politècnica de Valencia, Camino de Vera s/n 46022, Valencia (Spain)

(5) Department of Architecture, Built environment and Construction engineering (ABC), Politecnico di Milano, Piazza Leonardo da Vinci 32, 20133, Milan (Italy)

*_ｃorresponding author, e-mail: gabriele.milani@polimi.it

\begin{abstract}
Aim of the present paper is to numerically study the bond behavior of curved masonry specimens externally strengthened by Carbon Fiber Reinforced Polymer systems (CFRP). A simple 1D-modeling approach is presented to this aim, where the coupled behavior between shear and normal stresses developing at the reinforcement/masonry interface level is specifically introduced to properly account for the role played by the curvature radius. The model is indeed enriched by the introduction of shear stress-slip laws able to account for the beneficial friction effect, when compression normal stresses develop at the interface level and the reduction of the slip strength corresponding to the de-cohesion in presence of normal stresses in tension. Considering some case studies derived from the current literature, consisting of shear-lap bond tests of curved masonry specimens characterized by different curvatures of the bonded surface and different strengthening configurations, the validation of the proposed approach is carried out. In particular, two modeling strategies are considered and critically compared: the first one, denoted as approach (A), where the presence of the mortar joints is neglected, and the second one, denoted as approach (B), where mortar joints are specifically introduced in the model. Finally, the results obtained by using the proposed simple approach are compared with those obtained from both sophisticated FE numerical models and theoretical formulas deduced form the current literature.
\end{abstract}

Keywords: FRP; masonry curved structures; FE modeling; delamination; 1D coupled interface model.

\section{Introduction}

A large amount of the recent literature points out the centrality of the bond mechanism for studying the performance of fiber reinforced polymer systems (FRPs) for the strengthening and the rehabilitation of structures. Indeed, experimental tests mainly concerning shear lap bond tests were carried out in order to investigate the role of different factors such as the type of the strengthening system, the characteristics of the masonry material composing the substrate, the modalities of application of the strengthening system and, in case of masonry unit-mortar assemblages, the characteristics of mortar joints, on the bond mechanism of 
FRPs externally applied to masonry substrates [1]-[15]. These studies are a useful support for the development and validation of numerical and theoretical models generally based on the main assumption to consider that, during the de-bonding process, the damage only affects a thin layer of the material placed between the FRP-strengthening and the substrate (denoted interface), whilst the other components (substrate and FRP-strengthening) behave in the elastic stage.

The interface concept was indeed extensively employed for the development of numerical analyses of both concrete and masonry constructions. In particular, considering a meso-scale modelling level of unreinforced masonry, Page [16] suggested the use of interfaces between bricks by introducing a yield surface for the behavior of interfaces which only works in tension and shear. On the other hand, Lourenço [17] introduced modifications in the Page's model mainly concerning a compressive cap for the yield surface which allows to account for crushing of the masonry bricks within the joints. The model proposed by Lourenço specifically considers an elastic behavior for the elements composing the bricks and non-linear behavior concentrated into the interface elements used for modeling the joints. This model was generalized by Oliveira and Lourenco [18] for studying the cyclic behavior of masonry walls subjected to in-plane loads. More recently, Dolatshahi and Aref [19] proposed a modelling approach where the bricks composing the masonry panel are subdivided into a number of rigid elements and the elasticity and plasticity are introduced by using line-interface elements. For the interface elements, the relation between the tractions and the relative displacement is directly introduced in the model by considering the nonlinear behavior of the materials composing the masonry panel at the interface level. In Aref and Dolatshahi [20] a threedimensional modeling approach still based on the use of interface elements for simulating the interaction between masonry blocks was proposed for studying the cyclic response of masonry panels. The numerical simulations conducted by the authors underlined the accuracy and robustness of the proposed modeling approach. A similar approach was also used in Dolatshahi and Aref [21] for studying the response of masonry walls subjected to different sets of multi-directional loading combinations considering both monotonic and cyclic quasi-static loading protocols.

The above studies show the advantages and the potentialities in using modeling approaches based on interface elements for modeling the interaction among different components of structural systems.

In the case of strengthening systems applied on structural supports, the use of interface elements for modelling the interaction between the masonry support and the reinforcement leads to a significant simplification regarding the derivation of the parameters at the basis of theoretical/numerical models, which can be directly obtained from shear-lap tests. At the same time, a substantial simplification also concerns the finite element modeling phase [22]-[28]. Indeed, although the models based on the assumption of a perfect adhesion between FRPs and masonry substrate allow to exclude the identification of the parameters characterizing the behavior of the masonry/FRP interface (the debonding mechanism is directly modeled as a damage phenomenon affecting the material composing the substrate), such approach turns to be quite hard to tackle, because of the utilization of complex damage plasticity models which are needed to properly describe crack propagation into the substrate. A further complication is undoubtedly represented by mortar joints, which are planes of weakness where cracks preferentially propagate.

For the above reasons, modeling strategies based on the use of interface elements still remain the most appealing approaches for numerical analyses finalized to investigate the bond behavior of FRPs applied on masonry supports.

The majority of the interface modeling approaches available in the literature for the study of the bond behavior of FRPs are based on the introduction of cohesive zones at the interface level, by usually assuming a debonding mechanism which occurs under the tangential loading only or largely dominated by this failure mode (mode II). This assumption, which results realistic for FRPs applied on substrates with a flat configuration, could be not adequate in case of applications on curved substrates where, on the contrary, a coupling between mode II and mode I mechanisms assumes a relevant role in the debonding process [29][34]. 
Recently, Grande and Milani [32] have presented a simple but effective numerical model for the study of the bond behavior of FRPs externally applied on curved masonry substrates which straightforwardly introduces at the interface level coupled cohesive laws for considering a mixed mode de-bonding mechanism. In continuation with this research activity, the authors here present a 1D-modeling approach based on the use of springs elements enriched by the introduction of a shear stress-slip constitutive law for the reinforcement/substrate interface able to account for the interaction between shear and normal stresses, ruled by friction at the interface between the reinforcement and the substrate. Two novel modeling strategies are proposed and critically compared, denoted respectively as approach (A), where the presence of mortar joints is neglected and approach (B), where mortar joints are specifically taken into consideration. The validation of the proposed approach is made by considering ad-hoc experimentation carried out by the authors [33] consisting of shear-lap bond tests involving curved masonry specimens with different radius values and different strengthened configurations. Finally, a comparison with FE advanced numerical models [34] and theoretical formulas [32], both deduced from the current literature, is also presented.

\section{Modelling approach}

The numerical analyses presented in the paper are developed by using a simple 1D-FE modelling approach, denoted in the following Spring-Model, able to reproduce the bond behavior of FRP-strengthening systems externally applied on curved masonry substrates. Indeed, as presented in detail in the following sections, thanks to the introduction of specific constitutive laws and yield domains, the model is able to account for the interaction between shear and normal stresses developing at the FRP-masonry interface level during the de-bonding process.

\subsection{Spring-Model}

The Spring-Model here considered refers to the work proposed by some of the authors in [32]. It mainly consists in a simple schematization of masonry samples externally strengthening by FRPs through linear and nonlinear spring elements (Figure 1). Indeed, according to this model, the system FRP-interface-substrate is meshed by means of a single row of elements all characterized by translational degrees of freedom only. In particular, springs with a linear-elastic behavior are specifically introduced to model the masonry substrate and the FRP-strengthening: these springs connect among them the nodes of the substrate and the nodes of the strengthening and they are characterized by the following equivalent stiffness coefficients $k_{b}^{E}$ and $k_{f}^{E}$ :

$$
\begin{aligned}
& k_{b}^{E}=\frac{E_{b} A_{b}^{E}}{L_{E}} \\
& k_{f}^{E}=\frac{E_{f} A_{f}^{E}}{L_{E}}
\end{aligned}
$$

where: 
$L_{E}$, the springs length, represents the dimension of the mesh composing the global model of the specimen; $E_{b}$ and $E_{f}$ are respectively the Young's modulus of the material composing the substrate and the FRPstrengthening; $A_{b}$ and $A_{f}$ are the cross section area of the support and the reinforcement respectively.

Two types of zero-length nonlinear springs are introduced for the interface layer. In particular, springs which only activate for the tangential component of the relative displacement between the strengthening and the substrate nodes, $\Delta_{t}^{E}=u_{i}^{E, \bar{x}}-u_{k}^{E, \bar{x}}$ (denoted in the following as 'interface shear spring') are introduced to account for the mode II mechanism; springs which only activate for the component of the relative displacement between the strengthening and the substrate nodes orthogonal to the substrate, $\Delta_{n}^{E}=u_{i}^{E, \bar{y}}-u_{k}^{E, \bar{y}}$ (denoted in the following as 'interface normal spring') are introduce to account for the mode I mechanism.

The element stiffness matrix $\underline{\underline{K}}^{E}$ is then dependent on the relative displacements of both the interfaces and it results:

$$
\overline{\underline{K}}^{E}\left(\Delta_{t}^{E}, \Delta_{n}^{E}\right)=\left[\begin{array}{cccccccc}
k_{b}^{E}+k_{t}^{E}\left(\Delta_{t}^{E}, \Delta_{n}^{E}\right) & -k_{t}^{E}\left(\Delta_{t}^{E}, \Delta_{n}^{E}\right) & 0 & 0 & -k_{b}^{E} & 0 & 0 & 0 \\
-k_{t}^{E}\left(\Delta_{t}^{E}, \Delta_{n}^{E}\right) & k_{f}^{E}+k_{t}^{E}\left(\Delta_{t}^{E}, \Delta_{n}^{E}\right) & 0 & 0 & 0 & -k_{f}^{E} & 0 & 0 \\
0 & 0 & k_{n}^{E}\left(\Delta_{n}^{E}\right) & -k_{n}^{E}\left(\Delta_{n}^{E}\right) & 0 & 0 & 0 & 0 \\
0 & 0 & -k_{n}^{E}\left(\Delta_{n}^{E}\right) & k_{n}^{E}\left(\Delta_{n}^{E}\right) & 0 & 0 & 0 & 0 \\
-k_{b}^{E} & 0 & 0 & 0 & k_{b}^{E} & 0 & 0 & 0 \\
0 & -k_{f}^{E} & 0 & 0 & 0 & k_{f}^{E} & 0 & 0 \\
0 & 0 & 0 & 0 & 0 & 0 & 0 & 0 \\
0 & 0 & 0 & 0 & 0 & 0 & 0 & 0
\end{array}\right]
$$

In particular, since the above matrix refers to the local coordinate system $(\bar{x}, \bar{y})$ of the element $E$ composing the mesh, the global stiffness matrix $\underline{\underline{K}}$ of the entire specimen in the global system is then obtained by assembling the element stiffness matrices rotated to the global system through the rotation matrix.

Finally, the introduction of the boundary conditions, reproducing the experimental tests, allows to derive the stiffness matrix $\underline{\underline{\tilde{K}}}$ of the specimen.

\subsection{Coupled behavior and constitutive laws}

For both the types of spring composing the interface, nonlinear constitutive laws are assumed and, in addition, a coupled behavior between shear and normal forces developing at the interface level is provided to properly account for the role played by the curvature radius of the FRP/masonry interface.

In particular, the influence of the forces $\mathrm{T}_{\mathrm{n}}$ arising in the interface normal springs (forces in compression or tension) on the forces $T_{t}$ of the corresponding interface shear springs, is specifically introduced in the model by considering the Mohr-Coulomb failure domain: 
$T_{t}=T_{t, 0}-T_{n} \tan (\psi)$

where $T_{t, 0}$ is the peak force arising in the interface shear springs in case of uncoupled behavior and $\psi$ is the friction angle characterizing the yield domain.

Regarding the constitutive laws of the interface shear springs, differently from the approach proposed in [32], a tri-linear symmetric $T_{t}-\Delta_{t}$ law including the friction effect in the de-bonding phase when compression forces arise at the reinforcement/substrate interface has been here introduced (see Figure 2). Such behavior is much more complex than that in [32], but more realistic.

In particular:

(a) pre-peak stage $\left(\Delta_{\mathrm{t}}<\Delta_{\mathrm{t}, 0}\right)$ - the influence of the behavior of the interface normal springs on the behavior of the interface shear springs is introduced by varying the strength of the interface shear springs and assuming the same value of the displacement corresponding to the peak $\left(\Delta_{t, 0}\right)$ :

$T_{t}=\left[1-\frac{T_{n}}{K_{t}\left|\Delta_{t}\right|} \tan \varphi\right] K_{t} \Delta_{t} \quad\left|\Delta_{t}\right| \leq \Delta_{t, 0}$

(b) post-peak stage $\left(\Delta_{\mathrm{t}, 0}<\Delta_{\mathrm{t}}<\Delta_{\mathrm{t}, \mathrm{f}}\right)$ - the effect of forces $\mathrm{T}_{\mathrm{n}}$ on forces $\mathrm{T}_{\mathrm{t}}$ leads to a variation of the displacement $\Delta_{\mathrm{t}, \mathrm{f}}$ at the end of the descending branch of the $\mathrm{T}_{\mathrm{t}}-\Delta_{\mathrm{t}}$ law, denoted in the following $\bar{\Delta}_{t, f}$ :

$T_{t}=\left[\left(\frac{\Delta_{t, f}-\left|\Delta_{t}\right|}{\Delta_{t, f}-\Delta_{t, 0}}-\frac{T_{n}}{K_{t} \Delta_{t, 0}} \tan \varphi\right) \frac{\Delta_{t, 0}}{\left|\Delta_{t}\right|}\right] K_{t} \Delta_{t} \quad \Delta_{t, 0}<\left|\Delta_{t}\right| \leq \bar{\Delta}_{t, f}$

where:

$\bar{\Delta}_{t, f}=\left[1-\frac{T_{n}}{K_{t} \Delta_{t, 0}} \tan \varphi\right]\left(\Delta_{t, f}-\Delta_{t, 0}\right)+\Delta_{t, 0}$

(c) post-softening stage $\left(\Delta_{t}>\bar{\Delta}_{t, f}\right)$ - the attainment of the displacement corresponding to the null value of $\mathrm{T}_{t}$ leads to the unloading of the interface shear springs only in the case of tensile forces $T_{n}$; on the contrary, a residual strength depending on the value of $T_{n}$ characterizes the $T_{t}-\Delta_{t}$ law of the interface shear springs in case of compression forces $\left(\mathrm{T}_{\mathrm{n}}<0\right)$ :

$\begin{cases}T_{t}=0 & \left|\Delta_{t}\right|>\bar{\Delta}_{t, f} \text { and } T_{n} \geq 0 \\ T_{t}=\left[\left(\frac{T_{n}}{K_{t} \Delta_{t, 0}} \tan \varphi\right) \frac{\Delta_{t, 0}}{\left|\Delta_{t}\right|}\right] K_{t} \Delta_{t} & \left|\Delta_{t}\right|>\bar{\Delta}_{t, f} \quad \text { and } T_{n}<0\end{cases}$

Regarding the $T_{n}-\Delta_{n}$ law introduced for the interface normal springs (Figure 2(b)), it is assumed a linear behavior in compression $\left(\Delta_{n}<0\right)$ :

$T_{n}=K_{n} \Delta_{n}$

followed by a non-linear behavior in tension $\left(\Delta_{n} \geq 0\right)$ :

$$
\left\{\begin{array}{lr}
T_{n}=K_{n} \Delta_{n} & \left|\Delta_{n}\right| \leq \Delta_{n, 0} \\
T_{n}=K_{n} \Delta_{n} \frac{\Delta_{n}-\Delta_{n, 0}}{\Delta_{n, f}-\Delta_{n, 0}} & \Delta_{n, 0}<\left|\Delta_{n}\right| \leq \Delta_{n, f} \\
T_{n}=0 & \left|\Delta_{n}\right|>\Delta_{n, f}
\end{array}\right.
$$


where $K_{n}$ is the slope of the $T_{n}-\Delta_{n}$ law in compression and in pre-peak phase in tension, $\Delta_{n, 0}$ is the normal displacement at the end of the ascending branch of the $T_{n}-\Delta_{n}$ law in tension, $\Delta_{n, f}$ is the normal displacement at the end of the descending branch of the $T_{n}-\Delta_{n}$ law in tension.

\section{Numerical analyses}

The numerical analyses here presented are performed by considering the Spring-Model, the constitutive laws and the coupling behavior presented in the previous paragraphs. The model is implemented in MatLab [35] throughout an iterative procedure based on the classic Newton-Raphson technique by selecting the displacement control approach. In particular, case studies derived from the current literature [33] consisting of shear lap bond tests of curved masonry specimens strengthened by FRPs are here considered for assessing the efficacy of the proposed modelling approach.

\subsection{Case studies}

The case studies here accounted for the validation of the proposed modelling approach are derived from the current literature [33]. They consist of single shear-lap bond tests involving masonry pillars externally strengthened by CFRP strips. In particular, as shown in (Figure 3), four types of specimen in terms of curvature radius and strengthening configuration are considered:

a. curved masonry specimen characterized by a radius equal to $1500 \mathrm{~mm}$ (R150) strengthened at the intrados;

b. curved masonry specimen characterized by a radius equal to $1500 \mathrm{~mm}$ (R150) strengthened at the extrados;

c. curved masonry specimen characterized by a radius equal to $3000 \mathrm{~mm}$ (R300) strengthened at the intrados;

d. curved masonry specimen characterized by a radius equal to $3000 \mathrm{~mm}$ (R300) strengthened at the extrados.

All the masonry specimens are composed of five clay bricks with interposed mortar joints made of lime and cement as binder. The authors performed standard tests on bare materials by deriving the average values of the properties summarized in Table 1.

The reinforcement is composed of a $100 \mathrm{~mm}$ wide unidirectional carbon fiber textile glued on the masonry prisms by means of a thin layer of epoxy resin. The main characteristics of the reinforcement, directly derived from the datasheet furnished by the producer, are summarized in Table 1.

Additionally, the authors also performed pull-off tests on reinforced bricks in compliance with [36] in order to evaluate the bond strength between the CFRP reinforcement and the substrate. In particular, the tests were performed on six bricks reinforced with a CFRP sheet and prepared with two partially drilled cores. A steel disc, having diameter equal to $75 \mathrm{~mm}$, was bonded to the surface of the reinforcement and pulled-off. The failure of the substrate was observed for all tested specimens. The bond strength was evaluated for each 
specimen by dividing the maximum pull-off force by the cross section area of the partial core: an average value equal to $1.15 \mathrm{MPa}$ was obtained [33].

The single lap shear tests were performed in [33] by pulling the top edge of the carbon fabric left unbounded. The specimens were constrained by a steel plate at the upper base and by a steel wedge at the lower base. Both the upper plate and the lower wedge were linked by four steel bars to ensure the stability of the specimens during the tests. In addition, the steel wedge was equipped with an additional steel plate to constrain the specimen toward its rotation. Further details can be found in [33].

\subsection{Parameters setting and analysis approaches}

The parameters characterizing the springs composing the Spring-Model are derived on the basis of the mechanical properties of materials composing the strengthening system and the support. In particular, the parameters at the basis of the of the laws selected for the interface shear springs in case of $T_{n}=0$, are carried out by using the formulas contained in [23] for the case of CFRPs applied on flat masonry substrates.

According to these formulas, a simple bi-linear $\tau-\Delta_{t}$ shear stress-slip law is considered for modeling the shear behavior of the reinforcement/support interface layer. The bond strength $\left(\tau_{0}\right)$ of the material composing the interface layer is assumed equal to the shear strength of the material composing the masonry substrate obtained by considering the Rankine-Mises yield domain. On the other hand, the mode II fracture energy $\left(\Gamma_{f t}\right)$ is derived in [23] by assuming a ' $S$ ' shape of the distribution of shear stresses developing along the bond length of the CFRP, and introducing simple equilibrium conditions. Finally, considering the shear modulus of the substrate material and the adhesive material, the initial slope of the ascending branch $\left(G_{e}\right)$ of the $\tau$ - $\Delta_{t}$ law, the value of the slip $\left(\Delta_{t, 0}\right)$ at end of the ascending branch and the slip at the end of the descending branch $\left(\Delta_{t, f}\right)$ are derived. Details concerning the formulas can be found in [23].

From the shear stress-slip law $\tau-\Delta_{t}$, the corresponding $T_{t}-\Delta_{t}$ law characterizing the behavior of each interface shear spring of the model is then obtained by simply multiplying the shear stress by the corresponding crosssection area of the shear spring.

Regarding the behavior of normal springs, the parameters characterizing their law have been directly settled on the experimental test results. In particular, the value of the tensile strength, representing the detachment of the reinforcement from the substrate along the direction orthogonal to the substrate, is assumed equal to the mean value of bond strength obtained from pull-off tests presented in [33]. The initial slope of the ascending branch of the $\sigma-\Delta_{\mathrm{n}}$ law is derived by using the following relation:

$$
G_{n}=\frac{1}{\frac{t_{a}}{E_{a}}+\frac{t_{m}^{*}}{E_{m}}}
$$

where: 
$t_{a}$ is the thickness of the adhesive (here assumed equal to $1 \mathrm{~mm}$ ); $t_{m}^{*}$ is the effective thickness of the support [23]; $E_{a}$ is the Young's modulus of the adhesive; $E_{m}$ is the Young's modulus of the support material (brick or mortar).

The parameters obtained throughout the procedure discussed above are summarized in Table 2. In particular, they are derived by considering only the characteristics of bricks (Approach (A)) and both the characteristics of the bricks and the mortar (Approach (B)). Indeed, the authors performed numerical analyses presented in the paper by considering two modeling approaches:

- Approach (A), where the presence of mortar joints among bricks is neglected: here the springs composing the model are characterized by the same parameters which are deduced by only considering the properties of the bricks;

- Approach (B), where the presence of both bricks and mortar joints is considered: here the parameters of the springs composing the model are derived by considering the properties of both the bricks and the mortar joints.

\subsection{Results and discussion}

The results obtained from the numerical analyses are presented in Figure 4 and Figure 5 in terms of load vs. displacement curves. In particular, in Figure 4 are reported the numerical curves derived by using the Approach (A) and the Approach (B) together with the curves emerged from the experimental tests. From these figures it is evident the influence of both the curvature of the masonry substrate and the configuration of the strengthening on the bond behavior of specimens. Indeed, by examining each plot it is possible to observe greater values of the peak load in the case of strengthening applied at the extrados respect to the application at the intrados. Moreover, while the post-peak behavior of specimens strengthened at the intrados is characterized by a nonsignificat variation of the load, the application of the strengthening at the extrados leads to a post-peak behavior with a remarkable hardening effect. Both these evidences are well captured by the proposed model thanks to the coupling behavior between shear stresses and normal stresses at the reinforcement/substrate interface level and the features of the introduced constitutive laws.

These evidences can be also observed from Figure 5 where the numerical curves deduced by using Approach (B) are reported for both curved and flat specimens. From the curves reported in Figure 5(a), it emerges indeed a reduction of the global force in the post-peak phase with respect to the flat case: this effect is due to the force in tension arising at the reinforcement/support interface when the strengthening is applied at the intrados. On the contrary, the curves of Figure 5(b), referring to the application of the strengthening at the extrados, underline an increase of the slope of the post-peak branch of curves depending on the value of the radius. Also in this case this effect is due to the coupling behavior between shear stresses and normal stresses arising at the reinforcement/substrate interface, and then to the activation of the friction effect between the reinforcement and the masonry substrate in the de-bonding phase.

Comparing the numerical curves obtained by using the two proposed approaches, it is possible to observe lower values of the force carried by the reinforcement in the post-peak phase for Approach (B), particularly 
for the specimen with a radius $\mathrm{R}=1500 \mathrm{~mm}$. This evidence mainly depends on the introduction of a tau-slip law for the interface springs located between the reinfocement and the mortar joints with a bond strength and a fracture energy significant lower than those corresponding to the interface springs located between the reinforcement and the bricks. Then, a early debonding phenomenon occurrs at the zones corresponding to the position of mortar joints, leading to a reduction of the global force together with a fluctuation of the postpeak branch of the numerical curves. In Figure 6 and in Figure 7 it is shown the status of the reinforcement/substrate interface for the curved specimen with a radius of $1500 \mathrm{~mm}$, strengthened at the intrados. In particular, considering the step corresponding to the attainment of a displacement value equal to $0.5 \mathrm{~mm}$, in these figures it is reported the shear stress status of the inteface (Figure 6) and the plot of shear stresses at the interface along the bond length (Figure 7), for both the Approach(A) and the Approach(B). From the figures it is evident the effect of considering different shear stress-slip laws for the interfaces along bricks and mortar joints.

Nevertheless, from the same figure it is also evident that the attainment of the peak of shear stresses occurrs at the same section of the bond length for both the accounted approaches. Indeed, although the debonding early occurs at some of the mortar joints, shear stresses continue to transfer to the adjacent zones throughout the strengthening (bridge effect).

Finally, considering the Spring-Model presented in the present research and the properties of springs specifically derived on the basis of the materials composing the specimens assumed as case studies, numerical analyses have been performed by considering additional values of the geometry radius: $750 \mathrm{~mm}$, $1500 \mathrm{~mm}, 3000 \mathrm{~mm}, 6000 \mathrm{~mm}$. The results obtained from the numerical analyses in terms of load evaluated at the same displacement level $(\mathrm{D}=0.5 \mathrm{~mm})$ are presented in Figure 9 together with the approximate formula proposed by Grande and Milani [32]. From the plot, it is evident the effect of the geometry curvature on load for both the case of reinforcement applied at the intrados and extrados. In particular, the effect becomes relevant for radius values lower than $3000 \mathrm{~mm}$. On the other hand, the comparison with the approximate formula shows in general a good agreement with the numerical results particularly for values of radius greater than $3000 \mathrm{~mm}$. Indeed, for lower values of the radius, the difference between numerical data and the approximate formula is more evident, particularly in the case of the reinforcement applied at the extrados. This outcome is strictly related to the novel interface model introduced by the authors in this Paper. Indeed, it accounts for the effect of the geometry curvature by coupling normal and shear stresses in a more precise manner and, differently from the model proposed by Grande and Milani [32], it considers a beneficial friction effect when compression normal stresses develop at the interface level and a reduction of the slip corresponding to the de-bonding when normal stresses in tension occurr at the interface level.

\section{Conclusions}

The paper has presented a simple approach for studying the bond behavior of CFRPs externally applied on curved masonry specimens. The proposed model is based on the use of a simple 1D schematization consisting of the assemblage of linear and nonlinear spring elements reproducing the support, reinforcement 
and support/reinforcement interface components. A coupling behavior between shear and normal forces at the interface level together with specific cohesive laws able to consider the beneficial friction effect when compression normal stresses develop at the interface level and the reduction of the slip corresponding to the de-cohesion in presence of normal stresses in tension, are also introduced in the model.

The results emerged from the proposed approach, benchmarked with reference to case studies derived from an ad-hoc conducted experimentation [33], have underlined the efficacy of the model to reproduce the experimental response. Indeed, besides the good approximation of the peak load, the proposed model is able to capture the effect of the curvature on the post-peak behavior of specimens thanks to the constitutive laws introduced for the interface springs and the coupling effect.

In Figure 8, for each specimen experimentally investigated, the experimental load-displacement curves together with numerical curves obtained from both the approaches proposed in the present research are reported (plus other approaches available in the current literature). In particular, in the plots the numerical curves deduced by using the approach proposed by Grande and Milani [32] are reported, which is based on the use of the same spring-model but with simpler constitutive laws, and the curves derived by the FEmodelling approach proposed by Bertolesi et al. [33], based on a three-dimensional heterogeneous micromodelling strategy by means of which all the constituent materials have been modelled separately and where the simulations are carried out with the FE commercial package Abaqus [37]. In the same plots (horizontal dotted lines), the values of the bond strength evaluated through the approximate formula proposed by Grande and Milani [32] are also reported.

From a detailed comparison among the results, the following considerations can be drawn:

- comparing the curves obtained with the proposed model and those deduced from the approach proposed in [33], a good agreement between the results obtained with the present procedure (based on the interface concept where the non-linear behavior of the whole model is concentrated), and those achieved using sophisticated (but computationally demanding) FE heterogeneous models, where the damage of all constituents is accounted;

- comparing the curves obtained from the proposed approach and those deduced from the approach proposed in [32], a better agreement with the experimental outcomes emerges in the case of the proposed approach. This is particular evident in the case of CFRPs applied at the extrados, where both the experimental curves and the numerical ones show a post-peak behavior with a relevant hardening effect;

- the approximate formula proposed in [32] allows a prediction of bond strength values similar to that obtained by using the proposed approach in the case of CFRPs applied at the intrados. Differently, significant differences emerge in the case of CFRPs applied at the extrados, where the present approach reproduces much better experimental evidences. This outcome has been also confirmed by the sensitivity analyses carried out in the last part of the paper. 


\section{References}

[1] Fedele R, Milani G. Assessment of bonding stresses between FRP sheets and masonry prisms during delamination tests. Comp Part B 2012;43:1999-2011.

[2] Aiello MA, Sciolti MS, Triantafillou TC. FRP- strengthened masonry: Bond aspects. FRPRCS-8 (CD-ROM) Univ of Patras. Patras, Greece 2007.

[3] Grande E, Imbimbo M, Sacco E. FRP-strengthening of masonry structures: Effect of debonding phenomenon. In: Proc.: VI Int Conf Struc Anal Hist Cons. Taylor and Francis London 2008:10171023.

[4] Oliveira D, Basilio I, Lourenço PB. Experimental bond behavior of FRP sheets glued on brick masonry. ASCE J. Compos Cons 2011;15(1):32-41.

[5] Grande E, Imbimbo M, Sacco E. Bond behavior of CFRP laminates glued on clay bricks: experimental and numerical study. Compos Part B Eng 2011;42(2):330-40.

[6] Grande E, Imbimbo M, Sacco E. Bond Behavior of Historical Clay Bricks Strengthened with Steel Reinforced Polymers (SRP). Materials. 2011;4(3):585-600.

[7] Valluzzi MR, Oliveira DV, Caratelli A, Castori G, Corradi M, de Felice G, et al. Round Robin Test For Composite-To-Brick Shear Bond Characterization. Mat and Struct - RILEM. 2012; 45(12):1761-1791.

[8] Caggegi C, Pensee V, Fagone M, Cuomo M, Chevalier L. Experimental global analysis of the efficiency of carbon fiber anchors applied over CFRP strengthened bricks. Constr Build Mater 2014;53:203-12. doi:10.1016/j.conbuildmat.2013.11.086.

[9] Fagone M, Ranocchiai G, Caggegi C, Briccoli Bati S, Cuomo M. The efficiency of mechanical anchors in CFRP strengthening of masonry: An experimental analysis. Compos Part B Eng 2014;64:1-15. doi:10.1016/j.compositesb.2014.03.018.

[10] Grande E, Imbimbo M. The role of the adhesive on the bond behavior of SRPs applied on masonry supports: Experimental and numerical study. Key Engineering Materials. 2015;624:652-659.

[11] Rotunno T, Rovero L, Tonietti U, Briccoli Bati S. Experimental Study of Bond Behavior of CFRPto-Brick Joints. J Compos Constr 2015;19:4014063 
[12] Grande E, Imbimbo M, Sacco E. Investigation on the bond behavior of clay bricks reinforced with SRP and SRG strengthening systems. Materials and Structures 2015; 48(11): 3755-70.

[13] Briccoli Bati S, Fagone M, Ranocchiai G. The effects of mortar joints on the efficiency of anchored CFRP sheets reinforcements of brick-masonry. Key Eng Mater 2015;624:575-83. doi:10.4028/www.scientific.net/KEM.624.575.

[14] Fagone M, Ranocchiai G, Briccoli Bati S. An experimental analysis about the effects of mortar joints on the efficiency of anchored CFRP-to-masonry reinforcements. Compos Part B-Engineering 2015;76:133-48. doi:10.1016/j.compositesb.2015.01.050.

[15] Capozucca R, Ricci V. Bond of GFRP strips on modern and historic brickwork masonry. Composite Structures, 2016, 140: 540-555.

[16] Page AW. Finite Elem Model Masonry. 1978;104:1267-85.

[17] Lourenco P. Computational strategies for masonry structures Ph.D. Netherlands: Delft Universty Press; 1996.

[18] Oliveira DV, Lourenco PB. Implementation and validation of a constitutive model for the cyclic behaviour of interface elements. In: Computational Mechanics in Portugal. 17-19 ed. Portugal: Elsevier Ltd; 2004. p. 1451-61.

[19] Dolatshahi KM, Aref AJ. Two-dimensional computational framework of meso-scale rigid and line interface elements for masonry structures. Engineering Structures 2011;33:3657-3667.

[20] Aref AJ., Dolatshahi KM. A three-dimensional cyclic meso-scale numerical procedure for simulation of unreinforced masonry structures. Computers and Structures 2013;20:9-23.

[21] Dolatshahi KM, Aref AJ. Multi-directional response of unreinforced masonry walls: experimental and computational investigations. Earthquake Engineering Structural Dynamics 2016;45(9):14271449.

[22] Fedele R, Milani G. Three-dimensional effects induced by FRP-from-masonry delamination. Compos Struct 2011;93(7):1819-31.

[23] Grande E, Imbimbo M, Sacco E. Simple model for the bond behavior of masonry elements strengthened with FRP. J Compos Constr 2011;15 (3):354-63. 
[24] Grande E, Milani G, Sacco E. Modelling and analysis of FRP-strengthened masonry panels. Engineering Structures. 2008;30(7): 1842-1860.

[25] Grande E, Imbimbo M, Sacco E. A beam finite element for the nonlinear analysis of masonry buildings strengthened with FRP. International Journal of Architectural Heritage. Conservation, Analysis, and Restoration. 2011;5(6):693-716.

[26] Briccoli Bati S, Fagone M, Rotunno T. Lower Bound Limit Analysis of Masonry Arches with CFRP Reinforcements: A Numerical Method. J Compos Constr 2013;17:366. doi:10.1061/(asce)cc.19435614.0000350.

[27] Fagone M, Rotunno T, Briccoli Bati S. The Groin Vaults of St. John Hospital in Jerusalem: An Experimental Analysis on a Scale Model. Int J Archit Herit 2016;10:903-918.

[28] Grande E, Imbimbo M. A simple 1D-Finite Element approach for the study of the bond behavior of masonry elements strengthened by FRP. Composites Part B. 2016;91:548-558.

[29] Basilio I. Strengthening of arched masonry structures with composite materials. PhD thesis, University of Minho, Department of Civil Engineering, Portugal October 2007, available at: http://www.civil.uminho.pt/masonry/Publications/Update_Webpage/2007_PhD_IsmaelBasilio.pdf.

[30] Malena M, de Felice G. Externally bonded composites on a curved masonry substrate: experimental results and analytical formulation. Composite Structures 2014; 112(1): 194-206.

[31] Basilio I, Fedele R, Lourenço PB, Milani G. Assessment of curved FRP-reinforced masonry prisms: experiments and modeling. Construction \& Building Materials 2014; 51: 492-505.

[32] Grande E, Milani G. Modeling of FRP-strengthened curved masonry specimens and proposal of a simple design formula. Composite Structures 2016; 158:281-290.

[33] Rotunno T, Fagone M, Bertolesi E, Grande E, Milani G. Single lap shear tests of masonry curved pillars externally strengthened by CFRP strips. Under review 2018

[34] Bertolesi E, Milani G, Fagone M, Rotunno T, Grande E. Micro-mechanical FE numerical model for masonry curved pillars reinforced with FRP strips subjected to single lap shear tests. Under review 2018

[35] MATLAB version 7.10.0. Natick, Massachusetts: The MathWorks Inc.;2010. 
COST_2018_1215 Revised version modifications highlighted in color GREEN

[36] ASTM C1583/C1583M-13. Standard Test Method for Tensile Strength of Concrete Surfaces and the Bond Strength or Tensile Strength of Concrete Repair and Overlay Materials by Direct Tension (Pull-off Method) 2013.

[37] Abaqus. Release 6.3. Theory and user's manuals. Pawtucket (RI, USA): Hibbit, Karlsson and Sorensen Inc.; 2003. 


\section{Figures}

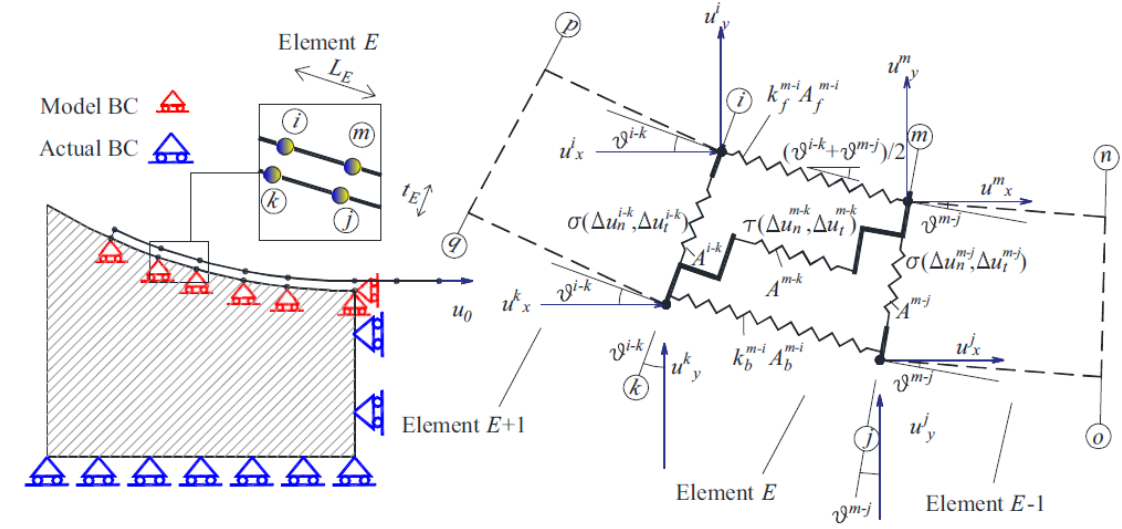

Figure 1. Schematization of the spring model (Grande and Milani, 2016). 


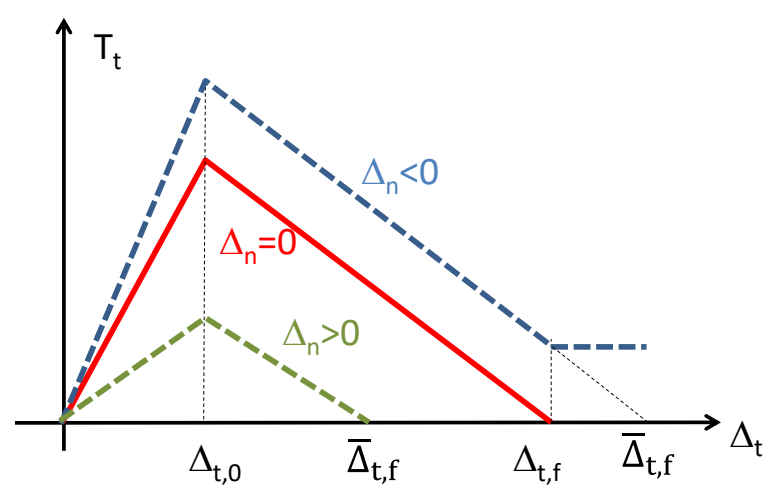

(a)

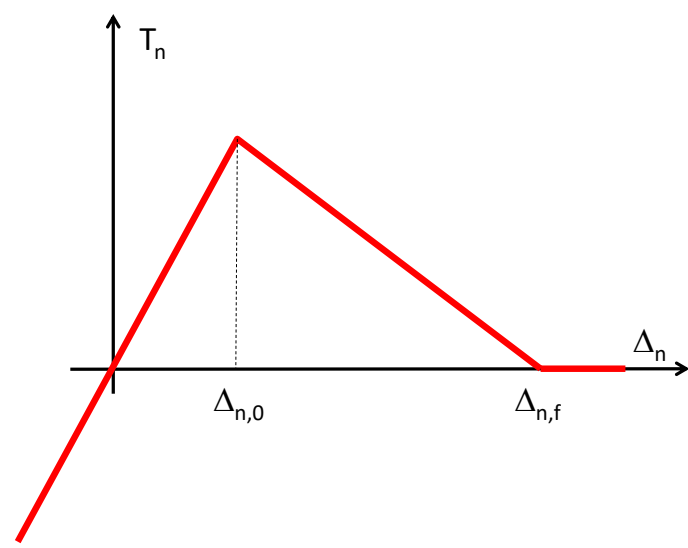

(b)

Figure 2. Models of the constitutive laws introduced for the (a) shear interface springs and (b) normal interface springs. 


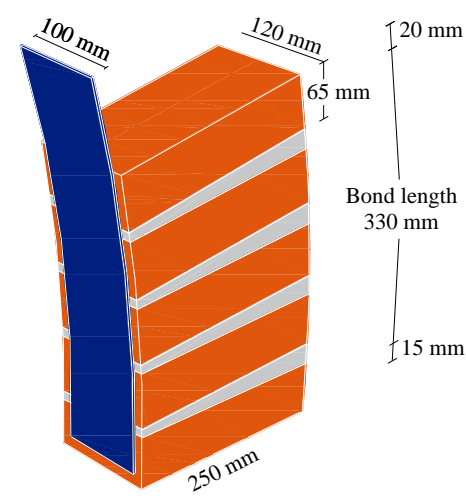

(a)

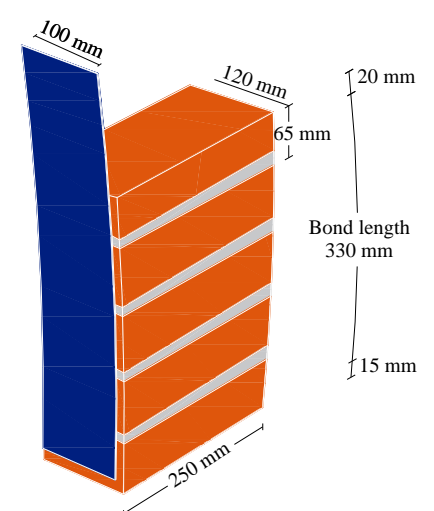

(c)

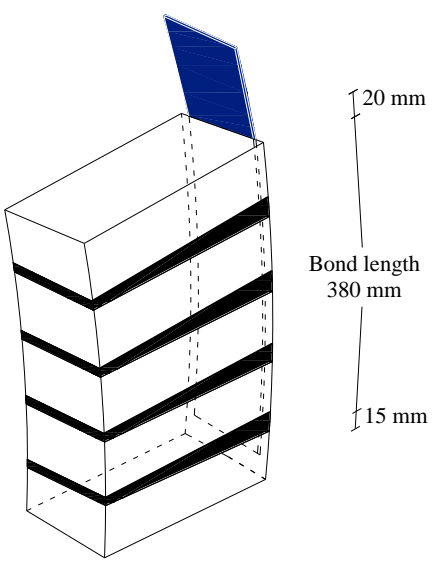

(b)

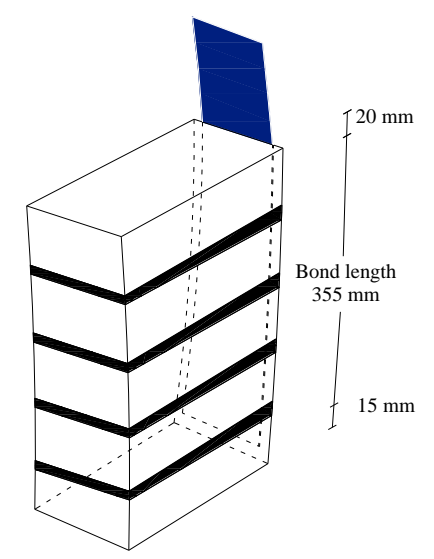

(d)

Figure 3. Geometry of the case studies accounted for the validation of the proposed model: (a) Curved Specimen INTRADOS-R150; (b) Curved Specimen EXTRADOS-R150; (c) Curved Specimen INTRADOS-R300; (d) Curved Specimen EXTRADOS-R300. 


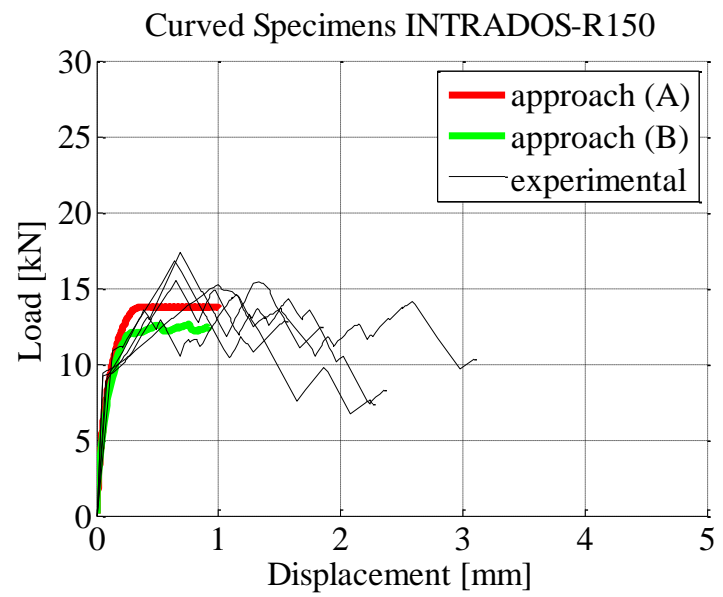

Curved Specimens EXTRADOS-R150

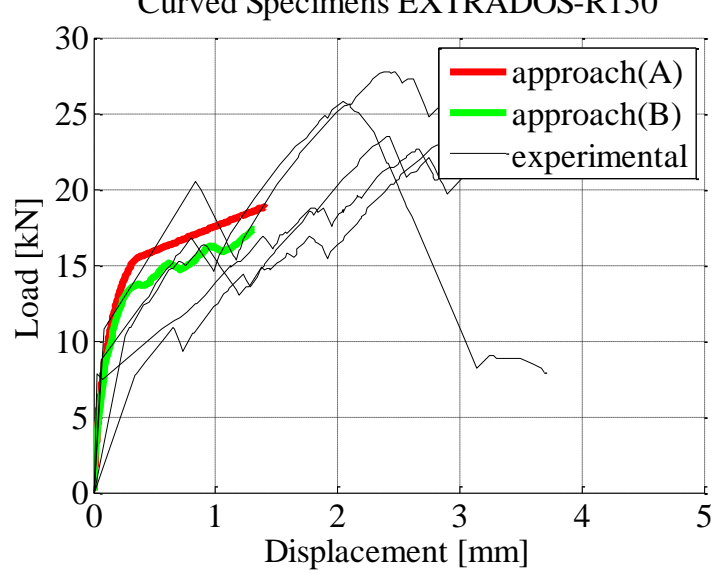

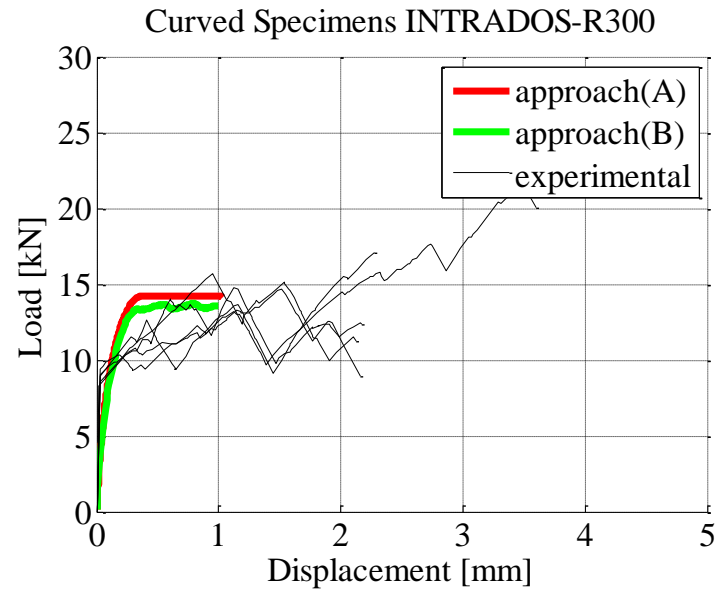

Curved Specimens EXTRADOS-R300

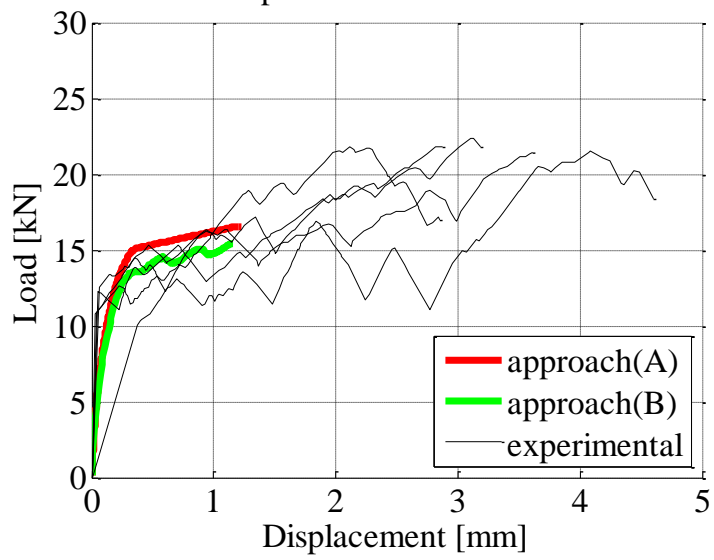

Figure 4. Force-Displacement curves derived from the Spring-Model by using the two selected approaches and ForceDisplacement curves derived from experimental tests. 

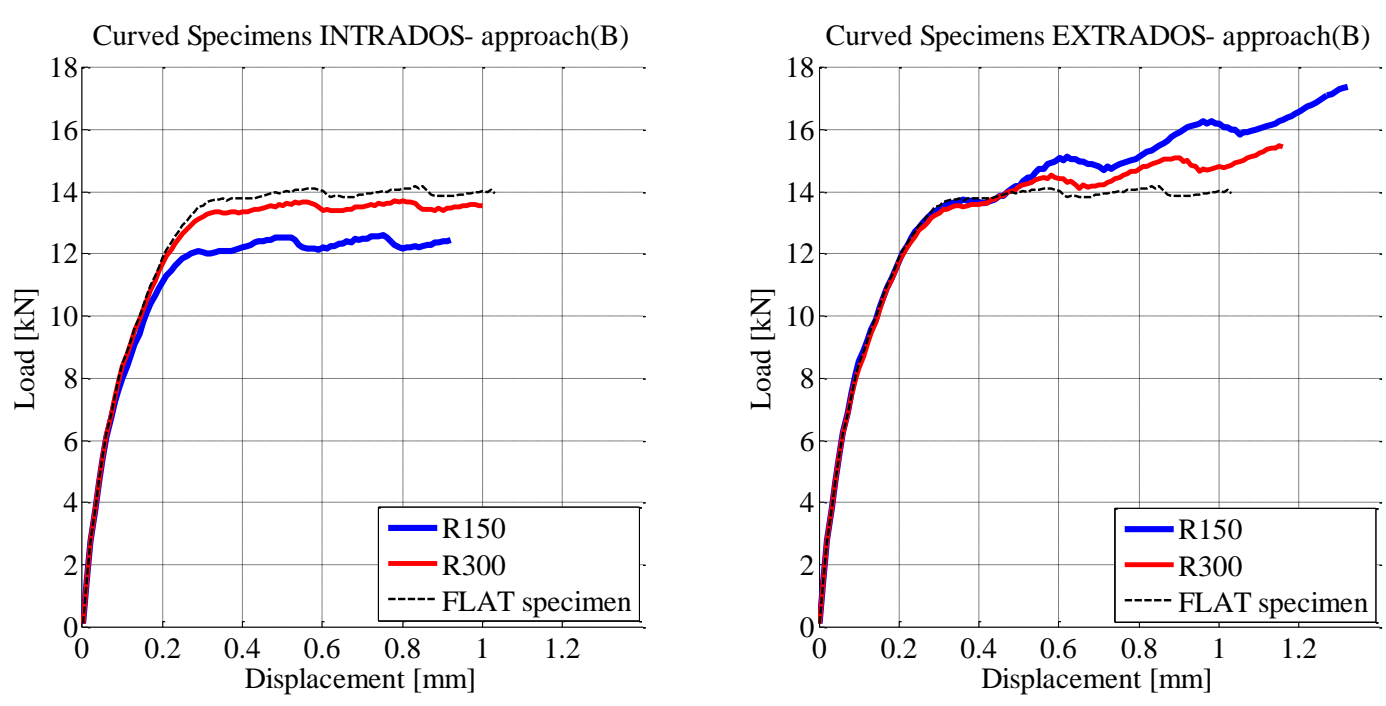

Figure 5. Spring-Model - Approach(B): comparison among numerical curves. 


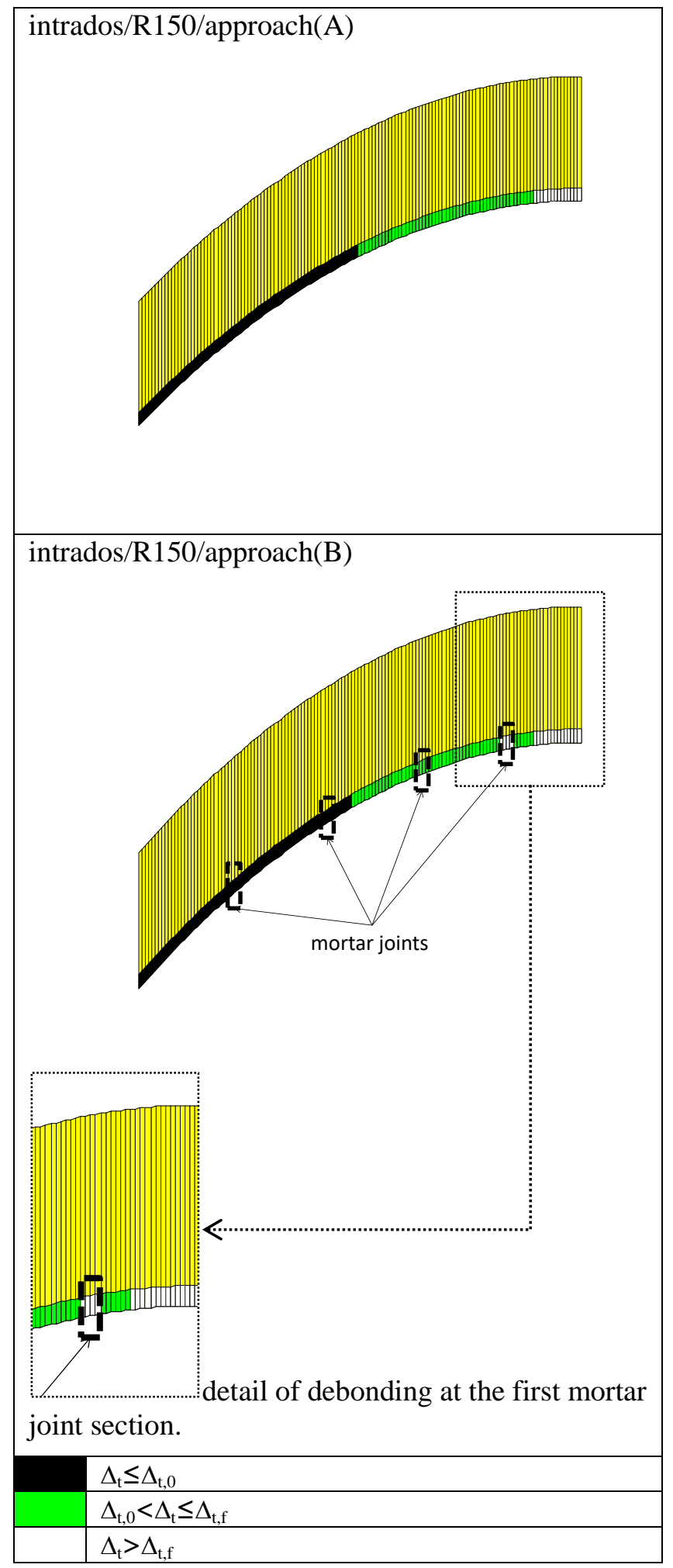

Figure 6. Shear stress status of the reinforcement/substrate interface: step at the displacement value $0.5 \mathrm{~mm}$. 


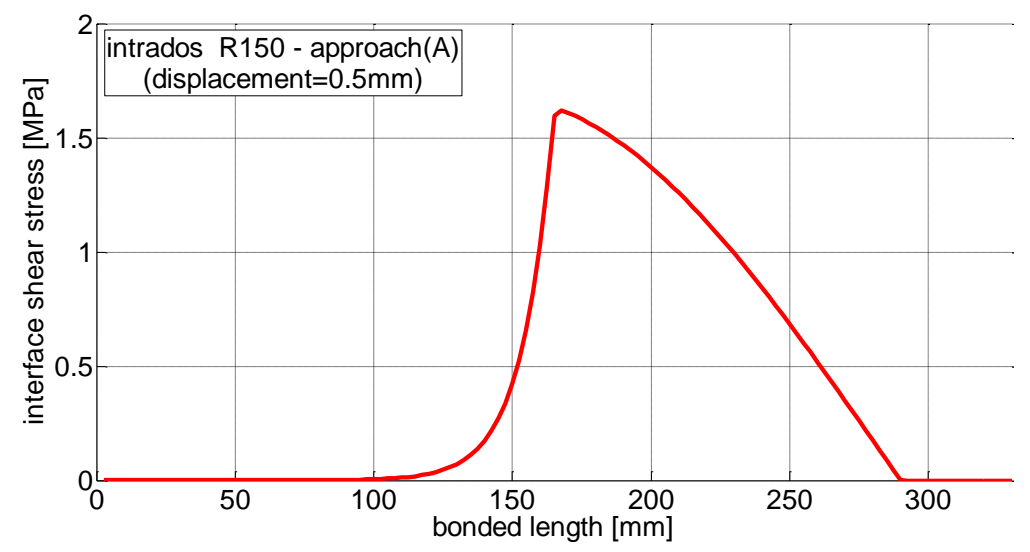

(a)

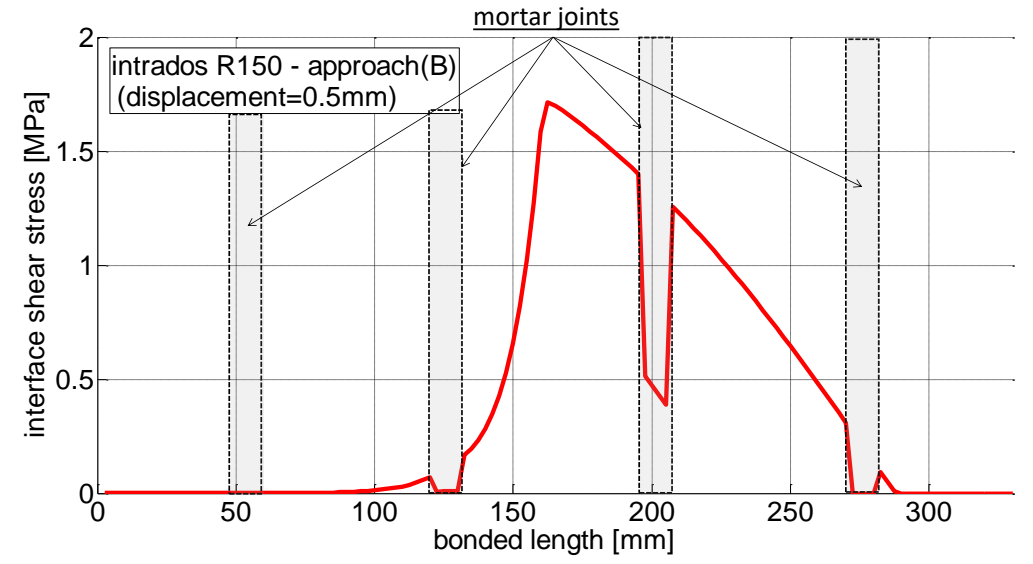

(b)

Figure 7. Shear stresses distribution at the reinforcement/substrate interface layer for the step corresponding to the displacement value $0.5 \mathrm{~mm}$ : (a) $\operatorname{approach}(\mathrm{A})$; (b) $\operatorname{approach}(\mathrm{B})$. 

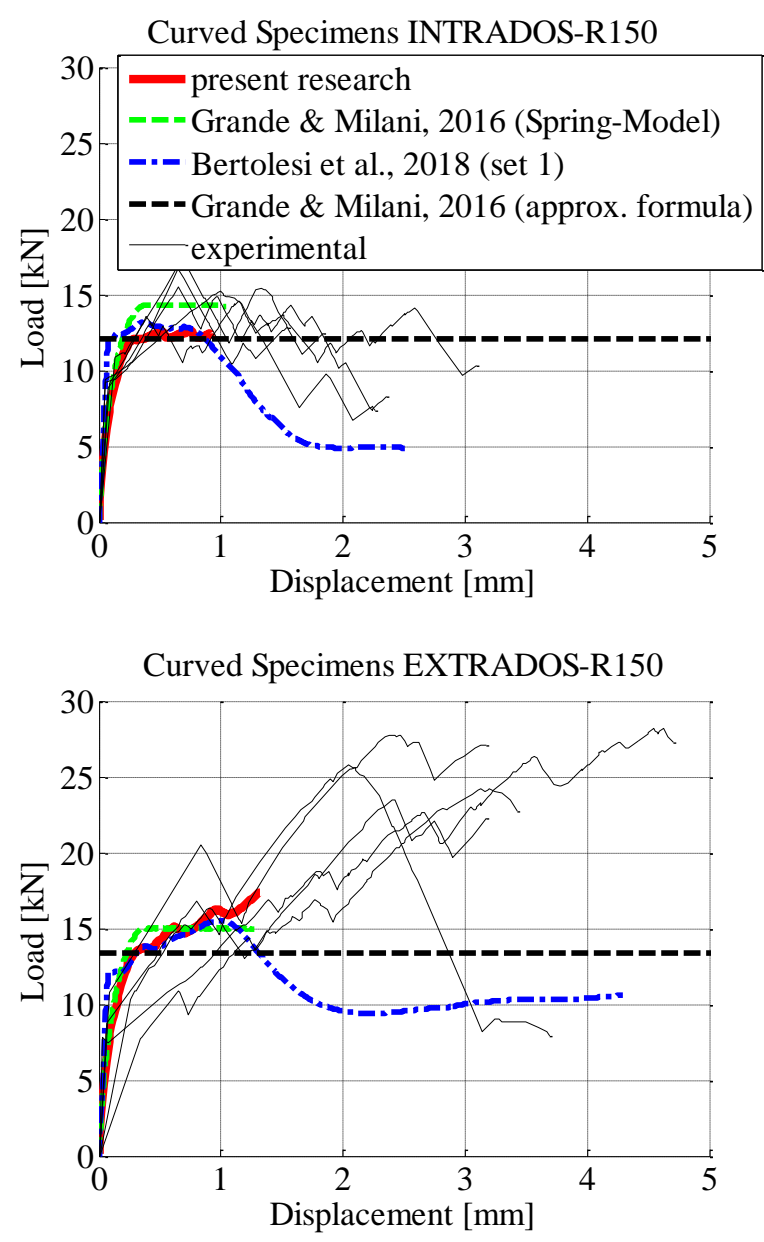
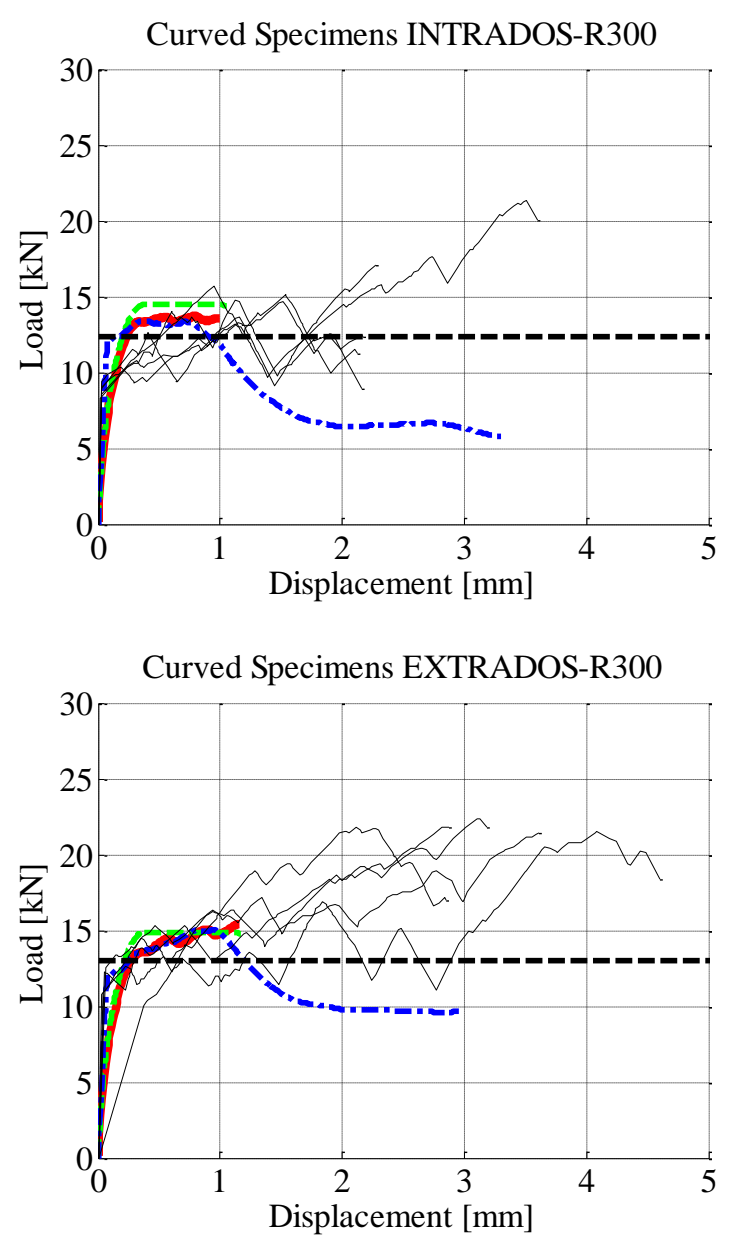

Figure 8. Comparison among experimental and numerical force-displacement curves derived from the present research and approaches available in the literature. 


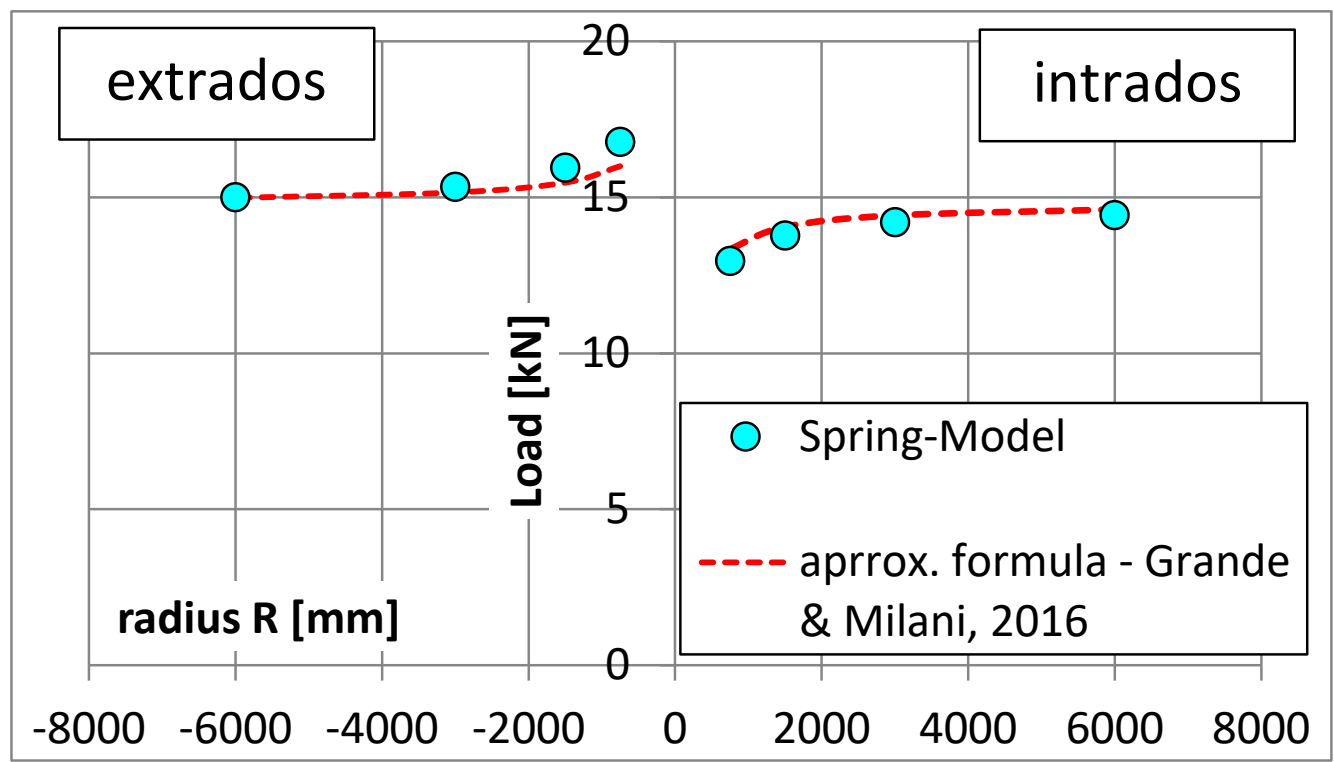

Figure 9. Sensitivity analysis considering different values of the geometry radius: numerical analyses (circle symbols) and approximate formula proposed by Grande and Milani, [32] (dotted line). 
COST_2018_1215 Revised version modifications highlighted in color GREEN

Tables

Table 1. Characteristics of materials composing the specimens.

\begin{tabular}{c|l|c|l}
\hline \multirow{4}{*}{ bricks } & average compressive strength & $\mathrm{f}_{\mathrm{bc}}[\mathrm{MPa}]$ & 20.1 \\
\cline { 2 - 4 } & average tensile strength & $\mathrm{f}_{\mathrm{bt}}[\mathrm{MPa}]$ & 2.5 \\
\cline { 2 - 4 } & average Young's modulus & $\mathrm{E}_{\mathrm{b}}[\mathrm{MPa}]$ & 8712 \\
\hline \multirow{3}{*}{ mortar } & average compressive strength & $\mathrm{f}_{\mathrm{mc}}[\mathrm{MPa}]$ & 20.1 \\
\cline { 2 - 4 } & average tensile strength (bending) & $\mathrm{f}_{\mathrm{mt}}[\mathrm{MPa}]$ & 2.5 \\
\hline \multirow{4}{*}{ strengthening } & $\mathrm{t}_{\mathrm{f}}[\mathrm{mm}]$ & 0.165 \\
\cline { 2 - 4 } & nominal thickness & $\mathrm{E}_{\mathrm{f}}[\mathrm{MPa}]$ & 250000 \\
\cline { 2 - 4 } & tensile elastic modulus & $\varepsilon_{\mathrm{f}}[\%]$ & 1.3 \\
\cline { 2 - 4 } & ultimate tensile strain & $\mathrm{f}_{\mathrm{ft}}[\mathrm{MPa}]$ & 3200 \\
\cline { 2 - 4 } & characteristic tensile strength & & \\
\hline
\end{tabular}


COST_2018_1215 Revised version modifications highlighted in color GREEN

Table 2. Parameters characterizing the interface springs.

\begin{tabular}{|c|c|c|c|}
\hline \multicolumn{4}{|c|}{ brick } \\
\hline \multirow{5}{*}{$\begin{array}{c}\text { interface } \\
\text { shear } \\
\text { behavior }\end{array}$} & bond shear strength & $\tau_{0}[\mathrm{MPa}]$ & 1.626 \\
\hline & fracture energy & $\Gamma_{f t}[\mathrm{~N} / \mathrm{mm}]$ & 0.264 \\
\hline & initial slope of the ascending branch of the $\tau-\Delta_{\mathrm{t}}$ law & $G_{t}\left[\mathrm{~N} / \mathrm{mm}^{3}\right]$ & 319.44 \\
\hline & slip at the end of the ascending branch & $\Delta_{t, 0}[\mathrm{~mm}]$ & 0.005 \\
\hline & slip at the end of the descending branch & $\Delta_{t, f}[\mathrm{~mm}]$ & 0.324 \\
\hline \multirow{2}{*}{$\begin{array}{c}\text { interface } \\
\text { normal } \\
\text { behavior }\end{array}$} & tensile strength & $f_{t}\left[\mathrm{~N} / \mathrm{mm}^{2}\right]$ & 1.15 \\
\hline & initial slope of the ascending branch of the $\sigma-\Delta_{n}$ law & $G_{n}\left[N / m^{3}\right]$ & 755 \\
\hline \multicolumn{4}{|c|}{ mortar } \\
\hline \multirow{5}{*}{$\begin{array}{c}\text { interface } \\
\text { shear } \\
\text { behavior }\end{array}$} & bond shear strength & $\tau_{0}[\mathrm{MPa}]$ & 0.919 \\
\hline & fracture energy & $\Gamma_{f t}[\mathrm{~N} / \mathrm{mm}]$ & 0.149 \\
\hline & initial slope of the ascending branch of the $\tau-\Delta_{\mathrm{t}}$ law & $G_{t}\left[\mathrm{~N} / \mathrm{mm}^{3}\right]$ & 26.305 \\
\hline & slip at the end of the ascending branch & $\Delta_{t, 0}[\mathrm{~mm}]$ & 0.035 \\
\hline & slip at the end of the descending branch & $\Delta_{t, f}[\mathrm{~mm}]$ & 0.324 \\
\hline \multirow{2}{*}{$\begin{array}{c}\text { interface } \\
\text { normal } \\
\text { behavior }\end{array}$} & tensile strength & $f_{t}\left[\mathrm{~N} / \mathrm{mm}^{2}\right]$ & 0.52 \\
\hline & initial slope of the ascending branch of the $\sigma-\Delta_{n}$ law & $G_{n}\left[N / \mathrm{mm}^{3}\right]$ & 71.37 \\
\hline
\end{tabular}

